\title{
Visual test for detection of pathological glycosaminoglycans excretion in mucopolysaccharidoses. A diagnostic tool in paediatric rheumatology
}

\author{
MJ Rua*, L Rodriguez, F Andrade, JA Prieto, M Montejo, P Sanjurjo and \\ L Aldamiz-echevarria
}

Address: Departement of Paediatrics Cruces Hospital, Baracaldo-Bilbao, Spain

* Corresponding author

\author{
from $15^{\text {th }}$ Paediatric Rheumatology European Society (PreS) Congress \\ London, UK. 14-17 September 2008 \\ Published: 15 September 2008 \\ Pediatric Rheumatology 2008, 6(SuppI I):PI57 doi:10.II86/I546-0096-6-SI-PI57
}

This abstract is available from: http://www.ped-rheum.com/content/6/SI/PI57

(c) 2008 Rua et al; licensee BioMed Central Ltd.

\section{Introduction}

Mucopolysacharidoses (MPS) are lysosomal storage disorders characterized by a deficiency/absence of a enzyme involved in the degradation of glycosaminoglycans (GAG) The diagnosis is frequently delayed as the quantification of GAG in urine is not routinely performed. We developed a qualitative method to detect high GAG levels in urine to provide an early diagnosis even in low suspicion cases of MPS in children.

\section{Methods}

Glycosaminoglicans react with 1,9-dimethylmethylene blue (DMB) in acidic medium yielding a pink colour. Optimum DMB concentration discriminates between pathological and normal excretion.

Test: $50 \mu \mathrm{l}$ of urine with $2 \mathrm{ml}$ of DMB solution. The final colour is compared against a scale.

The urine of 51 diagnosed MPS patients and 169 healthy child samples were essayed.

\section{Results}

A pink colour is developed when the sample contains more than $200 \mathrm{mg} / \mathrm{L}$ of GAG. The selected concentration gave a positive response in all untreated patients. Negative or dubious in Morquio and Sly diseases whose GAG excretion is low and in some patients under enzymatic treatment. Hurler, Hunter and Maroteau-Lamy were successfully detected, regardless of the creatinine clearance. Only two controls with high creatinine levels were dubious

\section{Conclusion and proposal}

GAG testing has proved to be useful for a rapid diagnosis of MPS with high GAG excretion.

This test provides an aid to rheumatologist in detecting patients with alerting musculoskeletal symptoms like joint stiffness, flexion contractures without evident inflammation, carpel tunnel syndrome or multiple trigger finger in cases of MPS-I.

We suggest using GAG testing in the screening of such dubious cases. 